Article

\title{
Penicillin Acylase from Streptomyces lavendulae and Aculeacin A Acylase from Actinoplanes utahensis: Two Versatile Enzymes as Useful Tools for Quorum Quenching Processes
}

\author{
Rodrigo Velasco-Bucheli ${ }^{1,+} \oplus$, Daniel Hormigo $1, \pm\left(\mathbb{C}\right.$, Jesús Fernández-Lucas ${ }^{1, \ddagger} \oplus$, \\ Pedro Torres-Ayuso ${ }^{1,}$, Yohana Alfaro-Ureña ${ }^{1}$, Ana I. Saborido ${ }^{1}$, Lara Serrano-Aguirre ${ }^{1}$, \\ José L. García $^{2}$, Fernando Ramón 1,ll, Carmen Acebal ${ }^{1}$, Antonio Santos ${ }^{3}$ (D), Miguel Arroyo ${ }^{1, \mathbb{I}(D)}$ \\ and Isabel de la Mata ${ }^{1, *, I}$ (D) \\ 1 Department of Biochemistry and Molecular Biology, Faculty of Biology, Complutense University (UCM), \\ José Antonio Novais 12, 28040 Madrid, Spain; rvelasc@unal.edu.co (R.V.-B.); \\ daniel.hormigo@universidadeuropea.es (D.H.); jesus.fernandez2@universidadeuropea.es (J.F.-L.); \\ pedro.torres-ayuso@nih.gov (P.T.-A.); yohanaalfaro@gmail.com (Y.A.-U.); asaborid@ucm.es (A.I.S.); \\ larase01@ucm.es (L.S.-A.); faramon@ucm.es (F.R.); cacebals@ucm.es (C.A.); marroyos@ucm.es (M.A.) \\ 2 Department of Environmental Biology, Biological Research Center (CSIC), Ramiro de Maeztu 9, \\ 28040 Madrid, Spain; jlgarcia@cib.csic.es \\ 3 Department of Genetics, Physiology and Microbiology, Faculty of Biology, UCM, José Antonio Novais 12, \\ 28040 Madrid, Spain; ansantos@ucm.es \\ * Correspondence: idlmata@ucm.es; Tel.: +34-913-944-150 \\ + Present address: Roche Diagnostics GmbH, Nonnenwald 2, 82377 Penzberg, Germany. \\ $\ddagger$ Present address: Applied Biotechnology Group, European University of Madrid, Tajo, s/n. Urb. El Bosque, \\ 28670 Villaviciosa de Odón, Madrid, Spain. \\ $\S$ Present address: Laboratory of Cell and Developmental Signaling, NCI ATRF, Frederick, MD 21701, USA. \\ || Present address: Screening and Compound Profiling Institut de Recherches Servier, 125 Chemin de Ronde, \\ 78290 Croissy-sur-Seine, France. \\ II These two researchers share the position of last author.
}

Received: 3 June 2020; Accepted: 26 June 2020; Published: 1 July 2020

Abstract: Many Gram-negative bacteria produce $N$-acyl-homoserine lactones (AHLs), quorum sensing (QS) molecules that can be enzymatically inactivated by quorum quenching $(Q Q)$ processes; this approach is considered an emerging antimicrobial alternative. In this study, kinetic parameters of several AHLs hydrolyzed by penicillin acylase from Streptomyces lavendulae (SIPA) and aculeacin A acylase from Actinoplanes utahensis (AuAAC) have been determined. Both enzymes catalyze efficiently the amide bond hydrolysis in AHLs with different acyl chain moieties (with or without 3-oxo modification) and exhibit a clear preference for AHLs with long acyl chains (C12-HSL > C14-HSL > C10-HSL > C8-HSL for SIPA, whereas C14-HSL > C12-HSL > C10-HSL > C8-HSL for AuAAC). Involvement of SlPA and AuAAC in QQ processes was demonstrated by Chromobacterium violaceum CV026-based bioassays and inhibition of biofilm formation by Pseudomonas aeruginosa, a process controlled by QS molecules, suggesting the application of these multifunctional enzymes as quorum quenching agents, this being the first time that quorum quenching activity was shown by an aculeacin A acylase. In addition, a phylogenetic study suggests that SIPA and $A u$ AAC could be part of a new family of actinomycete acylases, with a preference for substrates with long aliphatic acyl chains, and likely involved in QQ processes.

Keywords: penicillin acylase; aculeacin acylase; $\mathrm{N}$-acyl-homoserine lactone acylases; quorum quenching; biofouling 


\section{Introduction}

Quorum sensing (QS) is a bacterial cell-to-cell communication mechanism that allows bacteria to regulate a high diversity of biological functions such as bioluminescence, production of virulence factors, antibiotics and other secondary metabolites, and biofilm formation by releasing, detecting and responding to small, diffusible signal molecules called autoinducers [1,2]. The disruption of QS signaling, a process known as quorum quenching (QQ), is a promising alternative for controlling bacterial infections in human, animals or plants and anti-biofouling in membrane bioreactor systems [3-5]. Among the best-characterized QS molecules, $N$-acyl-homoserine lactones (AHLs) are the most commonly used by Gram-negative proteobacteria [6-9]. AHLs each consist of an acyl chain linked to a homoserine lactone core (HSL) by an amide bond [6]. Generally, AHL inactivation is accomplished by lactonases or acylases, although the inactivation by oxidoreductases acting on the $\mathrm{C} 3$ substituent in AHL acyl chain has also been reported [10]. Lactonases inactivate AHLs by hydrolyzing their lactone rings, but lactonolysis is reversible at acidic $\mathrm{pH}$, producing an active form [11,12], limiting the use of these enzymes, whereas acylases are more advantageous as QQ agents since they catalyze the irreversible hydrolysis of the amide bond [12]. Although numerous AHL acylases have been characterized, the link between $Q Q$ and the ability to gain a competitive advantage due to the production of these enzymes has not conclusively been demonstrated [13]. Recently, it has been described that certain beta-lactam antibiotic resistant bacteria show quorum quenching activity as well [14]. However, whether the molecules involved in both processes are the same is yet unknown [14]. Thus, due to the large number of putative bacterial enzymes that might be involved in QQ processes, further investigation is needed to gain insight into the roles of such enzymes in both environmental issues and biotechnological applications $[5,15,16]$.

The Ntn-hydrolase superfamily contains many enzymes with diverse activities, including $\beta$-lactam acylases, AHL acylases and proteasomes, among others [17]. Many of these enzymes have been classified according to their respective first reported activities, although this classification is not always necessarily in agreement with their true biological role [18]. Over the years, AHL acylase activity has been described for some penicillin acylases from Gram-negative bacteria, such as the penicillin G acylase from Kluyvera citrophila [19] and the penicillin V acylases (PVAs) from Pectobacterium atrosepticum and Agrobacterium tumefaciens [20]. Nevertheless, AHL degradation by penicillin acylases from filamentous Gram-positive bacteria has not been fully demonstrated so far.

Penicillin acylase from Streptomyces lavendulae ATCC 13664 (SlPA, formerly abbreviated as SlPVA in our previous reports) (EC 3.5.1.11) and aculeacin A acylase from Actinoplanes utahensis NRRL 12052 (AuAAC) (EC 3.5.1.70) are the unique described penicillin and echinocandin acylases, respectively, capable of efficiently hydrolyzing phenoxymethyl penicillin (penicillin $\mathrm{V}$ ), several natural aliphatic penicillins (such as penicillin $\mathrm{K}$, penicillin $\mathrm{F}$ and penicillin dihydro $\mathrm{F}$ ) and aculeacin $\mathrm{A}$ [21-24]. Astoundingly, both show very similar substrate specificity, with a marked preference for amides bearing long hydrophobic acyl moieties [21,22,24]. Moreover, these extracellular heterodimeric $(\alpha \beta)$ Ntn-hydrolases present interesting properties to be applied in the industrial production of semi-synthetic antibiotic and antifungal compounds in enzymatic bioreactors [25-30]. It is interesting that these enzymes are structurally related to the acyl-homoserine lactone acylase from Streptomyces sp. M664 [22], the only one characterized AHL acylase from filamentous bacteria [18,31], in contrast to the majority of QQ enzymes that belong to unicellular bacteria.

In the present study, we report the newly discovered AHL acylase activities of both SlPA and $A u \mathrm{AAC}$ and suggest their possible involvement in QS interference since they can inhibit formation of biofilms by Pseudomonas aeruginosa. In addition, high identities between both enzymes and AHL quorum quenching acylases were revealed by comparative sequence analysis. 


\section{Results and Discussion}

\subsection{Substrate specificity of SIPA and AuAAC towards different AHLs}

The substrate specificities of SlPA and AuAAC were analyzed by measuring initial rates and calculating kinetic parameters for the hydrolysis of several enantiopure L-AHLs (Tables 1 and 2, respectively).

Table 1. Kinetic parameters for SIPA using different AHLs *.

\begin{tabular}{rccc}
\hline \multicolumn{1}{c}{ Substrate } & $\boldsymbol{K}_{\mathbf{m}}(\mathbf{m M})$ & $\boldsymbol{k}_{\text {cat }}\left(\mathbf{s}^{-\mathbf{1}}\right)$ & $\boldsymbol{k}_{\text {cat }} / \boldsymbol{K}_{\mathbf{m}}\left(\mathbf{m M}^{\mathbf{- 1}} \mathbf{s}^{-\mathbf{1}}\right)$ \\
\hline C $_{8}$-HSL & $1.19 \pm 0.16$ & $22.9 \pm 1.2$ & 19.2 \\
3-oxo-C 8 -HSL & $0.93 \pm 0.14$ & $7.34 \pm 0.42$ & 7.9 \\
C $_{10}$-HSL & $0.25 \pm 0.04$ & $21.9 \pm 1.1$ & 87.6 \\
3-oxo-C 10 -HSL & $0.40 \pm 0.07$ & $14.8 \pm 1.0$ & 37.0 \\
C $_{12}$-HSL & $0.13 \pm 0.02$ & $19.3 \pm 1.1$ & 148.5 \\
3-oxo-C 12 -HSL & $0.22 \pm 0.03$ & $20.4 \pm 1.3$ & 92.7 \\
C $_{14}$-HSL & $0.039 \pm 0.007$ & $3.80 \pm 0.25$ & 97.4 \\
3-oxo-C 14 -HSL & $0.137 \pm 0.032$ & $10.8 \pm 1.9$ & 78.8 \\
\hline
\end{tabular}

${ }^{*}$ Reaction conditions: phosphate $\mathrm{pH} 8.0$ containing DMSO $20 \%(v / v)$ at $45{ }^{\circ} \mathrm{C}$.

Table 2. Kinetic parameters for AuAAC using different AHLs *.

\begin{tabular}{|c|c|c|c|}
\hline Substrate & $K_{\mathrm{m}}(\mathrm{mM})$ & $k_{\text {cat }}\left(\mathrm{s}^{-1}\right)$ & $k_{\text {cat }} / K_{\mathrm{m}}\left(\mathrm{mM}^{-1} \mathrm{~s}^{-1}\right)$ \\
\hline $\mathrm{C}_{8}-\mathrm{HSL}$ & $2.70 \pm 0.76$ & $24.7 \pm 3.6$ & 9.2 \\
\hline 3-oxo-C - $_{8}$ HSL & $0.45 \pm 0.14$ & $2.05 \pm 0.20$ & 4.6 \\
\hline $\mathrm{C}_{10}-\mathrm{HSL}$ & $0.19 \pm 0.03$ & $13.6 \pm 0.8$ & 71.6 \\
\hline 3-oxo-C ${ }_{10}$-HSL & $0.47 \pm 0.10$ & $4.45 \pm 0.39$ & 9.5 \\
\hline $\mathrm{C}_{12}$-HSL & $0.10 \pm 0.02$ & $8.15 \pm 0.56$ & 81.5 \\
\hline 3-oxo- $\mathrm{C}_{12}$-HSL & $0.17 \pm 0.03$ & $7.95 \pm 0.57$ & 46.8 \\
\hline $\mathrm{C}_{14}$-HSL & $0.013 \pm 0.003$ & $1.19 \pm 0.11$ & 91.5 \\
\hline 3-oxo-C ${ }_{14}$-HSL & $0.023 \pm 0.006$ & $1.79 \pm 0.23$ & 77.8 \\
\hline
\end{tabular}

${ }^{*}$ Reaction conditions: phosphate $\mathrm{pH} 8.0$ containing DMSO $20 \%(v / v)$ at $45{ }^{\circ} \mathrm{C}$.

As shown in Table 1, SlPA efficiently hydrolyzed several AHLs and their 3-oxo-derivatives. Although the highest catalytic constant $\left(k_{\text {cat }}\right)$ was found with $\mathrm{C}_{8}$-HSL $\left(22.9 \mathrm{~s}^{-1}\right)$, the enzyme was more efficient with substrates containing longer acyl chains. In fact, its catalytic efficiency $\left(k_{\text {cat }} / K_{\mathrm{m}}\right)$ was 4-fold higher with $\mathrm{C}_{10}$-HSL $\left(87.6 \mathrm{mM}^{-1} \mathrm{~s}^{-1}\right)$ or $\mathrm{C}_{14}$-HSL $\left(97.4 \mathrm{mM}^{-1} \mathrm{~s}^{-1}\right)$ and almost 8-fold higher when $\mathrm{C}_{12}$-HSL was used $\left(148.5 \mathrm{mM}^{-1} \mathrm{~s}^{-1}\right)$. The presence of a 3-oxo group had a negative impact on catalytic efficiency, but this effect was less pronounced as the length of the acyl chain increased. These data suggest that the amide group and the ketone at the C3' position of the acyl chain of AHLs could be important for enzyme-substrate interaction. Among the 3-oxo derivatives, the highest catalytic efficiency value corresponded to 3-oxo- $\mathrm{C}_{12}$ - $\mathrm{HSL}\left(92.7 \mathrm{mM}^{-1} \mathrm{~s}^{-1}\right)>3$-oxo- $\mathrm{C}_{14}-\mathrm{HSL}>3-\mathrm{oxo}-\mathrm{C}_{10}-\mathrm{HSL}$ $>3$-oxo-C C $_{8}$-HSL. SlPA did not show detectable activity on $\mathrm{C}_{4}$-HSL, and its activity against $\mathrm{C}_{6}-\mathrm{HSL}$ was poor. Likewise, the kinetic parameters for the AuAAC-catalyzed hydrolysis of different AHLs and their 3-oxo derivatives were also determined (Table 2), whose values were quite similar to those obtained using SlPA (Table 1).

Like SlPA, AuAAC exhibited hydrolytic activity towards $\mathrm{C}_{8}-\mathrm{HSL}>\mathrm{C}_{10}-\mathrm{HSL}>\mathrm{C}_{12}-\mathrm{HSL}>\mathrm{C}_{14}$-HSL, $\mathrm{C}_{8}$-HSL being the best substrate according to the observed catalytic constant $\left(24.7 \mathrm{~s}^{-1}\right)$. This preference for a $C_{8}$-acyl chain is in agreement with previous kinetic studies employing various aliphatic penicillins as substrates. In this sense, both enzymes were reported to display the highest catalytic constant with penicillin K (22.7 s ${ }^{-1}$ for SlPA and $33.3 \mathrm{~s}^{-1}$ for AuAAC, respectively) [21,24], a penicillin derivative which bears a $C_{8}$-acyl chain attached to 6-amino penicillanic acid (6-APA). In addition, $K_{m}$ values for AHLs with acyl chains longer than eight carbons were generally lower than those reported for aliphatic penicillins in both SlPA and AuAAC [21,24], pointing at the possible role of these enzymes in QQ processes. Although the activity towards 3-oxo derivatives was also detected, the highest 
catalytic efficiency value for $\mathrm{AuAAC}$ corresponded to 3-oxo- $\mathrm{C}_{14}$-HSL $\left(77.8 \mathrm{mM}^{-1} \mathrm{~s}^{-1}\right)>3$-oxo- $\mathrm{C}_{12}$-HSL $>3$-oxo- $\mathrm{C}_{10}$-HSL $>3-$-oxo- $\mathrm{C}_{8}-\mathrm{HSL}$, showing lower values than those observed for SlPA. Among all the substrates included in this study, the best catalytic efficiency was observed with $\mathrm{C}_{14}$-HSL $\left(91.5 \mathrm{mM}^{-1}\right.$ $\mathrm{s}^{-1}$ ). This preference of SlPA and AuAAC for unsubstituted AHLs in C3' position has been also observed in AHL acylases from Shewanella sp. MIB015 (AaC) [32] and Acinetobacter sp. Ooi24 (AmiE) [33]. Broad substrate specificity towards different AHLs and $\beta$-lactam antibiotics has also been described for other enzymes, besides SlPA and AuAAC. For instance, the extracellular AHL acylase from Streptomyces sp. M664 (AhlM) efficiently hydrolyzes $\mathrm{C}_{8}$-HSL, $\mathrm{C}_{10}$-HSL and 3-oxo- $\mathrm{C}_{12}-\mathrm{HSL}$, whereas its deacylation activity towards short-acyl chain AHLs, $\mathrm{C}_{6}$-HSL and 3-oxo- $\mathrm{C}_{6}$-HSL was relatively low, and was negligible using $\mathrm{C}_{4}$-HSL as the substrate [31], as is the case for SlPA and AuAAC. In addition, AhlM also shows acylase activity towards penicillin $\mathrm{G}$, expanding its substrate specificity to different structures such as $\beta$-lactam antibiotics.

It was believed that AHL acylase from Acidovorax sp. MR-S7 (MacQ) shows the broadest substrate specificity, since it can deacylate various AHLs, ranging from $C_{6}$ to $C_{14}$ in length, and different $\beta$-lactams antibiotics, including penicillin derivatives (penicillin $\mathrm{G}$, ampicillin, amoxicillin, and carbenicillin) and cephalosporin derivatives (cephalexin and cefadroxil) [34]. Nevertheless, no echinocandin acylase assays were reported for this enzyme.

It is important to point out that there is no report of kinetic parameters for AHLs by using AhlM and MacQ acylases. The activities of AhlM and MacQ acylases were measured by an AHL inactivation bioassay instead of the fluorescence HSL-OPA assay, which allows the quantification of the HSL released during the enzymatic reaction. Said bioassay has traditionally been used to check out qualitatively only the degradation or non-degradation of various AHLs ranging from $C_{6}$ to $C_{14}$ in length using AHL acylases from microorganisms like Ralstonia sp XJ12B (AiiD) [35], Pseudomonas aeruginosa PAO1 (PvdQ and QuiP) [36,37], Pseudomonas syringae B728a (HacA and HacB) [38], Anabaena sp. PCC7120 (AiiC) [39], Shewanella sp. MIB015 (AaC) [32], Deinococcus radiodurans R1 (QqaR) [40] and K. citrophila DSM 2660 (KcPGA) [19].

To the best of our knowledge, the kinetics of enzyme reactions catalyzed by AHL acylases have not been studied in detail, and only a few reports indicate catalytic efficiency values for different AHLs in order to deep into substrate specificity of these enzymes. In this sense, the HSL-OPA method was used to carry out kinetic studies of AHL acylases from P. aeruginosa PA01 (PA0305 and PvdQ) [36,41] and KcPGA [19], and penicillin V acylases form Pectobacterium atrosepticum (PaPVA) and Agrobacterium tumefaciens (AtPVA) [20], but employing few AHLs as substrates.

Using 3-oxo- $\mathrm{C}_{12}$-HSL as the substrate, $k_{\text {cat }} / K_{m}$ values for $\mathrm{PaPVA}\left(135 \mathrm{mM}^{-1} \mathrm{~s}^{-1}\right), \operatorname{AtPVA}\left(26.8 \mathrm{mM}^{-1}\right.$ $\left.\mathrm{s}^{-1}\right)$, PA0305 $\left(78 \mathrm{mM}^{-1} \mathrm{~s}^{-1}\right)$ and PvdQ $\left(5.8 \mathrm{mM}^{-1} \mathrm{~s}^{-1}\right)$ could be compared to those observed for SlPA $\left(92.7 \mathrm{mM}^{-1} \mathrm{~s}^{-1}\right)$ and $A u \mathrm{AAC}\left(46.8 \mathrm{mM}^{-1} \mathrm{~s}^{-1}\right)$ (Tables 1 and 2), although different reaction conditions (such as $\mathrm{pH}$, temperature, buffer concentration and DMSO concentration) were employed in every case. The kinetic data support the strong activities of both SlPA and AuAAC towards 3-oxo- $\mathrm{C}_{12}-\mathrm{HSL}$. In the case of PaPVA and AtPVA, the plot of the reaction velocity (v) as a function of 3-oxo- $\mathrm{C}_{12}-\mathrm{HSL}$ concentration followed a sigmoidal pattern, and an allosteric behavior was attributed to the low substrate solubility in the reaction medium that did not allow one to reach substrate saturation [20], even though DMSO at $0.8 \%(v / v)$ was used to enhance 3-oxo- $\mathrm{C}_{12}$-HSL solubility. In contrast, a hyperbolic behavior was observed in the case of SlPA and $A u A A C$, likely due to the presence of DMSO at $20 \%(v / v)$ in the reaction that allowed total solubilization of higher concentrations of 3-oxo- $\mathrm{C}_{12}$-HSL during the kinetic study (Figure S1). It is worth mentioning that activities of SlPA and $A u A A C$ were not affected in the presence of $20 \%$ DMSO. 
Finally, using $\mathrm{C}_{12}-\mathrm{HSL}$ as the substrate, the $k_{\text {cat }} / K_{m}$ value for PA0305 [41] at $\mathrm{pH} 7.5$ and $30{ }^{\circ} \mathrm{C}$ in the absence of DMSO $\left(1.4 \mathrm{mM}^{-1} \mathrm{~s}^{-1}\right)$ was significantly lower than the ones described for SlPA $\left(148.5 \mathrm{mM}^{-1} \mathrm{~s}^{-1}\right)$ and $A u A A C\left(81.5 \mathrm{mM}^{-1} \mathrm{~s}^{-1}\right)$ at $\mathrm{pH} 8.0$ and $45^{\circ} \mathrm{C}$ in the presence of DMSO at $20 \%(v / v)$ (Tables 1 and 2). Although kinetic constants have been reported for KcPGA employing $\mathrm{C}_{6}$-HSL and 3-oxo- $\mathrm{C}_{6}$-HSL, enzymatic activity of SlPA and $A u$ AAC with these substrates was too low to perform an adequate kinetic characterization. In fact, a low catalytic activity $\left(k_{\text {cat }}\right)$ was also observed in the case of KcPGA using $\mathrm{C}_{6}$-HSL $\left(0.03 \mathrm{~s}^{-1}\right)$ and 3-oxo-C 6 -HSL $\left(0.06 \mathrm{~s}^{-1}\right)$ [19].

\subsection{Quorum Quenching Role of SIPA and AuAAC}

The AHL acylase activities of both SIPA and AuAAC suggests that these enzymes may be involved in QQ processes. To demonstrate this hypothesis two different bioassays were used. The first one exploits QS-reporting violacein production by Chromobacterium violaceum CV026, and the second one monitors biofilm formation by P. aeruginosa.

Results of the forward bioassay carried out with C. violaceum $\mathrm{CV} 026$ employing $\mathrm{C}_{6}-\mathrm{HSL}$ and $\mathrm{C}_{8}-\mathrm{HSL}$ as inducers are shown in Figure 1. C. violaceum CV026 produced violacein only when $\mathrm{C}_{6}$-HSL (or $\mathrm{C}_{8}-\mathrm{HSL}$ ) was added to the agar plate (Figure 1B vs. Figure 1A) and such production was slightly inhibited in the presence of SIPA (Figure 1C). The inhibition of violacein production was more evident when the AHL was previously incubated with SlPA (for $24 \mathrm{~h}$ at $40^{\circ} \mathrm{C}$ ) and further added to the medium (Figure 1D). This inhibitory effect was higher with $\mathrm{C}_{8}$-HSL as expected due the higher catalytic efficiency of SIPA on this compound (Table 1). Similar results were observed for AuAAC in the forward bioassay of $\mathrm{C}_{8}$-HSL hydrolysis (data not shown). Furthermore, the effect of both enzymes in violacein production by enzymatic hydrolysis of long-chain AHLs was detected by reverse bioassays (data not shown).

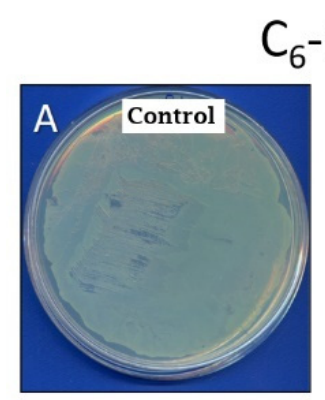

\section{$\mathrm{C}_{6}-\mathrm{HSL}$}
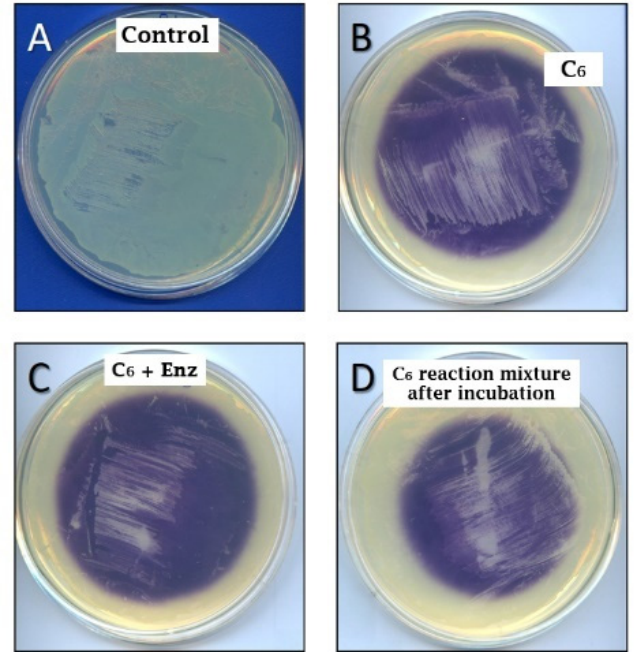

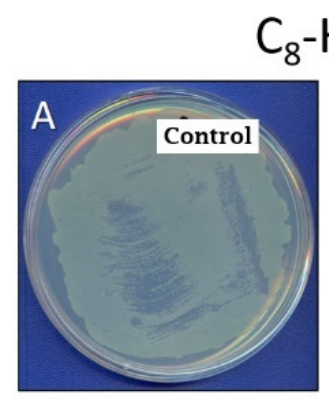

$\mathrm{C}_{8}-\mathrm{HSL}$
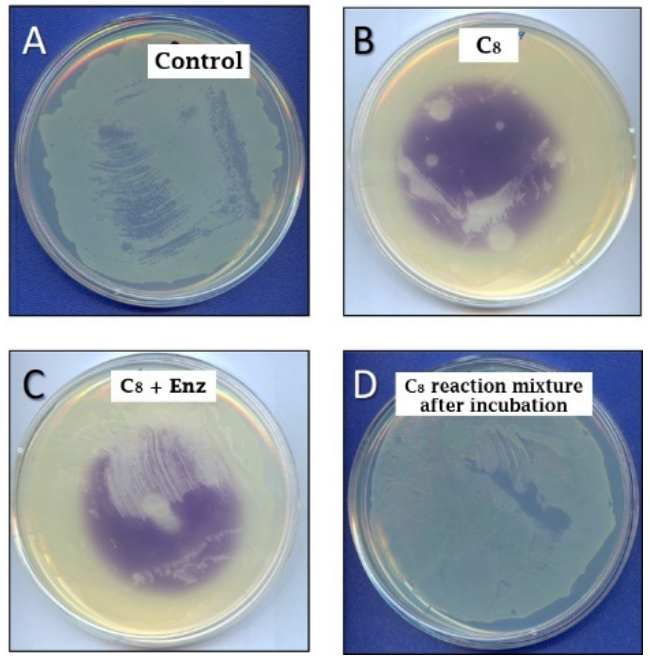

Figure 1. CV026-based forward bioassay of AHL hydrolysis by SlPA. $\mathrm{C}_{6}$-HSL and $\mathrm{C}_{8}$-HSL were used as inducers of violacein production. (A) C. violaceum CV026 without inductor; (B) C. violaceum CV026 grown in the presence of AHL; (C) C. violaceum CV026 grown in the presence of a mixture of AHL and SlPA (in vivo assay); (D) C. violaceum CV026 grown in the presence of a pre-incubated reaction mixture of AHL and SlPA (in vitro assay). $\mathrm{C}_{6}$-HSL concentration was $20 \mathrm{mM}$, whereas $\mathrm{C}_{8}$-HSL concentration was $5 \mathrm{mM}$. 
QS interference by the wild-type strains producing SlPA and $A u \mathrm{AAC}$ was confirmed using C. violaceum CV026-based forward bioassay (Figure 2B,C). Previously, C. violaceum CV026 was assessed to produce violacein when $\mathrm{C}_{8}$-HSL was added to the agar plate (Figure $2 \mathrm{~A}$ ), and this production was not affected by the presence of wild-type S. lividans (Figure 2D). Finally, AHL acylase cleavage was also demonstrated employing the recombinant strains of Streptomyces lividans CECT 3376 and CECT 3377, expressing SlPA and AuAAC respectively (Figure 2E,F), demonstrating that both enzymes can interfere in quorum sensing signaling in vivo.

On the other hand, SlPA was tested for its ability to disrupt formation of biofilms by P. aeruginosa, a a QS controlled process (Figure 3). When SlPA was added to the culture in its soluble form, disruption of biofilm formation was high (Figure 3C1), whereas it was only moderate when the enzyme was immobilized to silanized slides (Figure 3D1). In this sense, slide coating with SlPA was confirmed by immunodetection (Figures 3B2 and 4D2). On the contrary, biofilm formation was not affected in the absence of SIPA (Figure 3A1) or the presence of the heat-inactivated enzyme (Figure 3B1). Similar results were obtained when $A u \mathrm{AAC}$ was employed in the same experiment (data not shown).
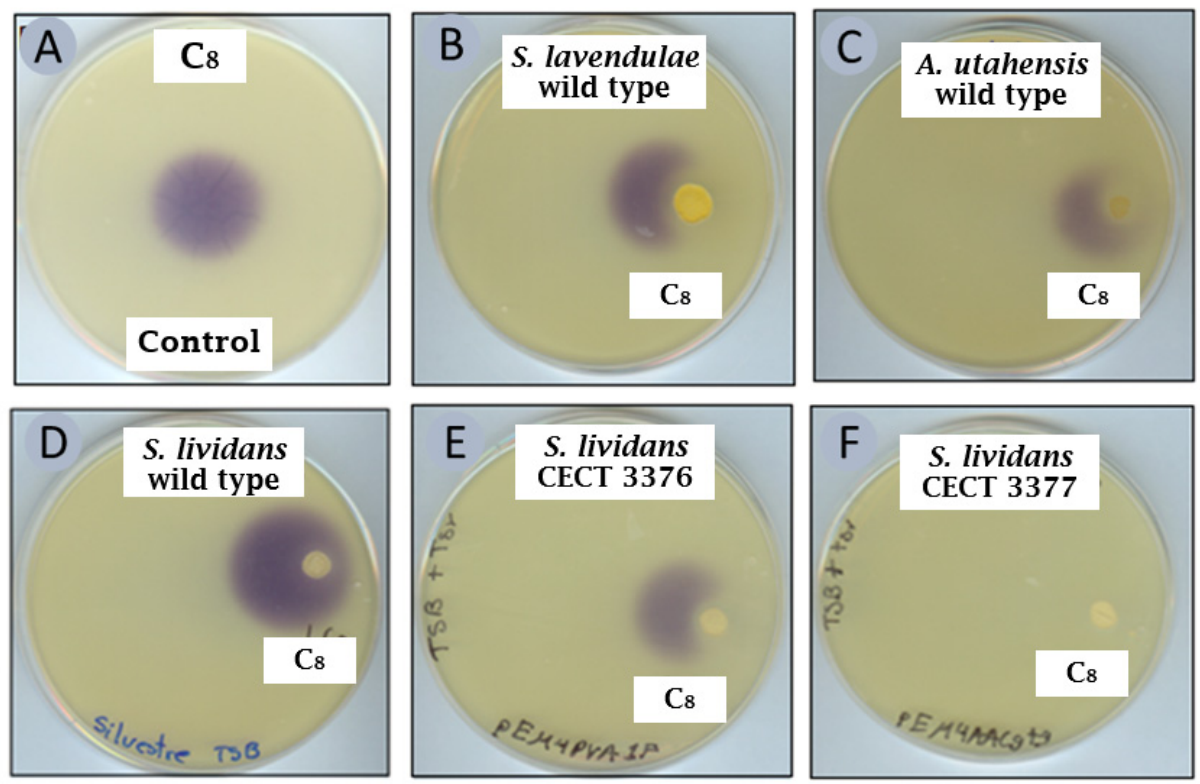

Figure 2. Detection of AHL degradation by recombinant S. lividans strains expressing SlPA and AuAAC. CV026-based bioassay was used to monitor $\mathrm{C}_{8}$-HSL cleavage. (A) C violaceum CV026 control (AHL non-degrading); (B) Streptomyces lavendulae; (C) Actinoplanes utahensis; (D) Streptomyces lividans (AHL non-degrading control); (E) recombinant Streptomyces lividans expressing SlPA (CECT 3376); and (F) recombinant Streptomyces lividans expressing AuAAC (CECT 3377).

These results suggest that these acylases can be used to combat the formation of biofilms by P. aeruginosa. Corneal, lung and burn wound infections caused by P. aeruginosa, and the production of virulence factors (and the biofilm differentiation) of this opportunistic pathogen, are regulated by two QQ signals such as 3-oxo- $\mathrm{C}_{12}$-HSL and $\mathrm{C}_{4}$-HSL $[1,42,43]$. Besides, 3-oxo- $\mathrm{C}_{8}$-HSL has demonstrated to increase cell-growth rate during the formation of $P$. aeruginosa biofilm on ultra-filtration membranes for advanced wastewater treatment [44]. In the present work, the presence of SlPA and AuAAC has significantly reduced P. aeruginosa biofilm formation, likely due to hydrolysis of different AHLs and 3-oxo-AHLs with long acyl-chains, and this effect suggests potential clinical and environmental applications. In fact, the role of the AHL-degrading enzymes to prevent biofilm formation in wastewater treatment plants (WWTPs) is under study, since the inhibition of biofilms on ultrafiltration membranes of membrane bioreactors (MBR) could solve biofouling problems and increase the useful lifespan of filtration membranes minimizing operational costs [5]. Further experiments are warranted to gain a better understanding on the practicality of this advanced technology for biofouling control in MBR 
systems. Additional studies on the $Q Q$ acylase activity of SlPA and $A u A A C$ are currently in progress in order to assess their inhibitory capacity of biofilm formation by bacteria inhabiting WWTPs.

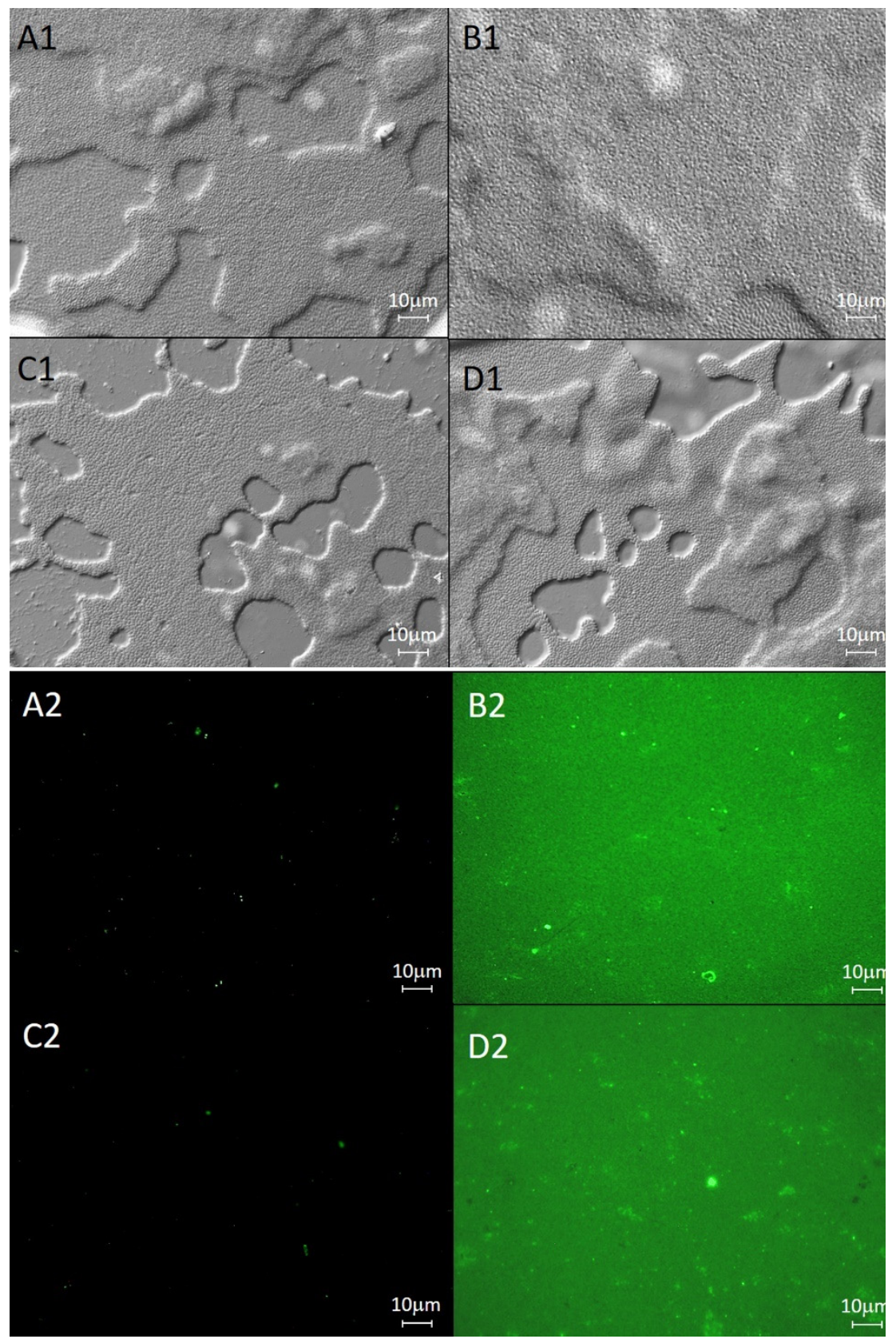

Figure 3. Disruption of Pseudomonas aeruginosa biofilm development on glass slides. Images acquired after $24 \mathrm{~h}$ in the following conditions: (A1): No SlPA addition. (B1): Heat-inactivated SlPA bound to silanized slides. (C1): SlPA addition in culture media. (D1): SlPA bound to silanized slides. SlPA attachment to slides was determined by using an Alexa Fluor 488 dye goat anti-rabbit whole antibody conjugate. (A2): No SlPA addition. (B2): Heat-inactivated SlPA bound to silanized slides. (C2): SlPA addition in culture media. (D2): SlPA bound to silanized slides. Microphotographs were obtained using a differential interference contrast (DIC) microscopy (A1-D1) at $\times 1000$ total magnification, or an Olympus BX61 epifluorescence microscope (A2-D2) at $\times 400$ total magnification. 


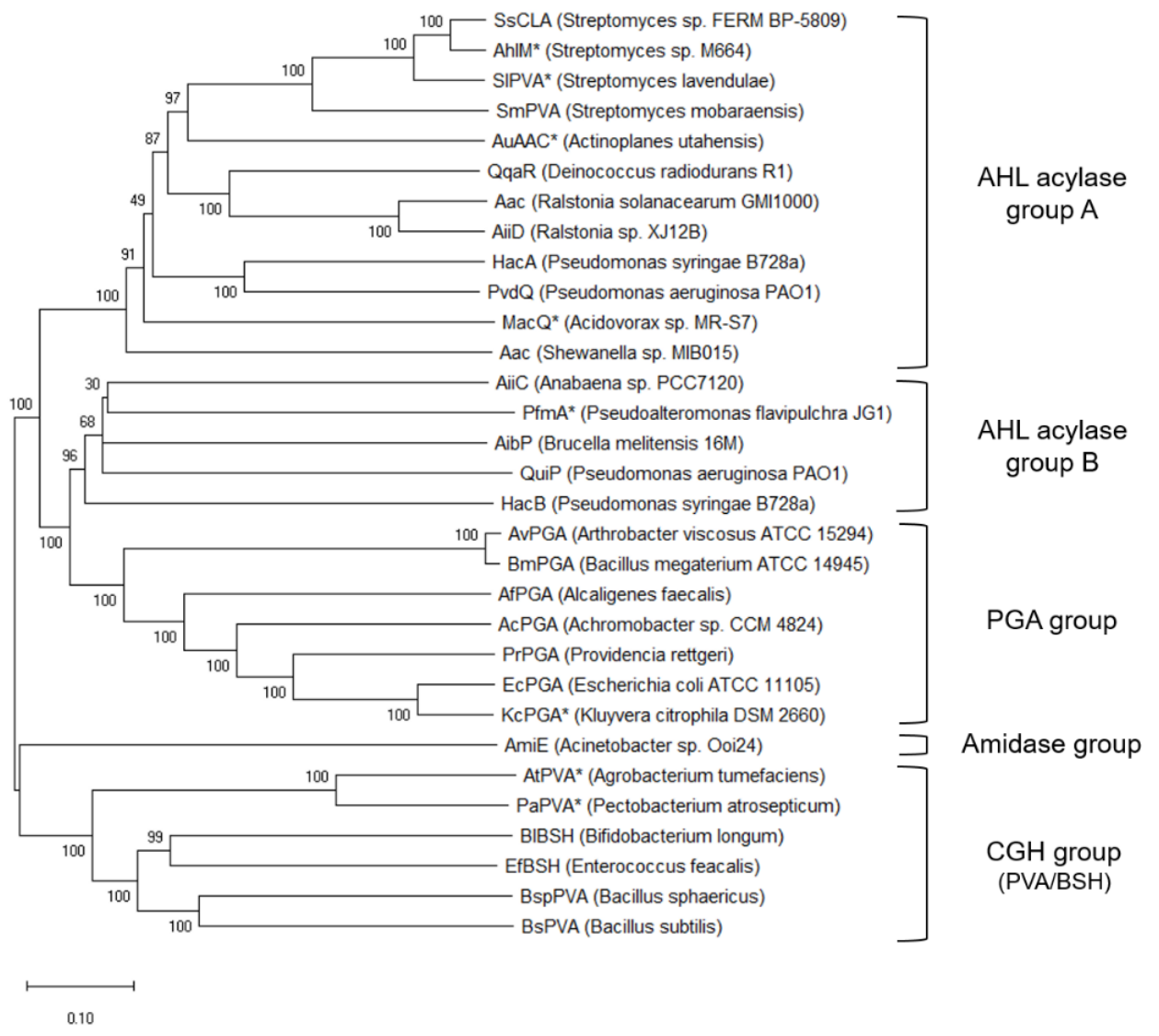

Figure 4. Molecular phylogenetic analysis of SlPA and AuAAC in the context of the Ntn-hydrolase superfamily (accession numbers in the NCBI server). Ntn-hydrolases with reported AHL acylase activity: AiiD, from Ralstonia sp. XJ12B (AAO41113); PvdQ, from Pseudomonas aeruginosa PAO1 (AAG05773); AhlM, from Streptomyces sp. M664 (AAT68473); QuiP, from P. aeruginosa PAO1 (AAG04421); HacA, from Pseudomonas syringae B728a (AAY37014); HacB, from P. syringae B728a (AAY39885); AiiC, from Anabaena sp. strain PCC7120 (BAB75623); Aac, from Shewanella sp. strain MIB015 (BAF94155); QqaR, from Deinococcus radiodurans R1 (WP_010889514); MacQ, from Acidovorax sp. MR-S7 (BAV56778), PfmA, Pseudoalteromonas flavipulchra JG1 (ASS36259); AmiE, Acinetobacter sp. Ooi24 (BAP18758); AibP, from Brucella melitensis (AAL53453); Aac, from Ralstonia solanacearum GMI1000 (WP_011002462); SlPA, from Streptomyces lavendulae ATCC 13664 (AAU09670), AuAAC, from Actinoplanes utahensis NRRL 12052 (WP_043523659). Ntn-hydrolases with reported penicillin G acylase activity: EcPGA, from Escherichia coli ATCC 11105 (P06875); KcPGA, from Kluyvera citrophila DSM 2660 (P07941); AcPGA, from Achromobacter sp. strain CCM 4824 (AAY25991); BmPGA, from Bacillus megaterium ATCC 14945 (Q60136); AfPGA, from Alcaligenes faecalis ATCC 19018 (AAB71221); AvPGA, from Arthrobacter viscosus ATCC 15294 (P31956); and PrPGA, from Providencia rettgeri (AAP86197). Ntn-hydrolases with reported penicillin V acylase activity: SmPVA, from Streptomyces mobaraensis (BAF51977); AtPVA, from Agrobacterium tumefaciens (5J9R); PaPVA, from Pectobacterium atrosepticum (4WL2); and BspPVA, from Bacillus sphaericus (3PVA). Ntn-hydrolases with reported bile salt hydrolase activity: BlBSH, from Bifidobacterium longum (2HF0), and EfBSH, from Enterococcus feacalis (4WL3). Ntn-hydrolases with reported cyclic lipopeptide acylase activity were as follows: SsCLA, from Streptomyces sp. FERM-BP5809 (BAD07025). Bifunctional acylases (with both penicillin acylase and AHL acylase activities) are indicated by asterisks, but among them only SlPA and AuAAC present aculeacin A acylase activity as well. The evolutionary history was inferred using the neighbor-joining (NJ) method within the 3DM and MEGA X packages. The optimal tree with the sum of branch length $=8.78001801$ is shown. This analysis involved 31 amino acid sequences. All ambiguous positions were removed for each sequence pair (pairwise deletion option). There was a total of 965 positions in the final dataset. 


\subsection{Phylogenetic Analysis of SIPA and AuAAC Acylases}

To gain further knowledge on the role of the SlPA and AuAAC through the analysis of their evolution, the amino acid sequences of SlPA and AuAAC were compared in the context of the Ntn-hydrolases superfamily using 3DM a molecular class-specific information system built by multiple structure alignment and automated literature mining $[45,46]$. The 3DM system contained 12,567 sequences grouped into 13 subfamilies based on 179 available structures. The largest subfamily was "4HSTA" (glutaryl-7-ACA-alpha chain, containing 7155 sequences) (Figure S2). In contrast, both SlPA and $A u$ AAC were included in subfamily "5C9IA" (protein related to penicillin acylase, containing 955 sequences). The model protein of subfamily 5C9IA is the aforementioned MacQ, an AHL acylase from Acidovorax sp. MR-S7, active towards both AHLs and $\beta$-lactam antibiotics [47]. In addition, a phylogenetic study was performed using MEGA $X$ based on the amino acid sequences of 31 Ntn-hydrolases with reported amidase activities (Figure 4). The results showed that SlPA, AHL acylase from Streptomyces sp. M664 (AhIM) [31], cyclic lipopeptide acylase from Streptomyces sp. FERM BP-5809 (SsCLA) [48] and penicillin V acylase from Streptomyces mobaraensis (SmPVA) [49] are very close together in the phylogenetic tree, and these three enzymes are also near $A u A A C$. In this sense, there is moderate sequence identity of AuAAC with SmPVA (42.1\%), SlPA (42.3\%), AhlM (42.7\%) and SsCLA (42.9\%), whereas SlPA showed high identity with SmPVA (66.3\%), SsCLA (85.7\%) and AhlM (86.5\%), In contrast, both SIPA and AuAAC are very distant from those enzymes belonging to the group of penicillin G acylases (PGA group) and penicillin V acylases (PVA group) (Figure 4). In fact, our phylogenetic tree is quite similar to the one described recently by Kusada et al. who reported that Ntn-hydrolase family could be divided into three main groups: a $\beta$-lactam acylase group (that would correspond to our PGA group) and two AHL acylase groups (A and B) [34]. Our results are in agreement with this affirmation, and furthermore we have identified new members within each group (Figure 4). In this sense, HacB [38], QuiP [37], AibP [50], PfmA [51] and AiiC [39] would belong to the AHL acylase group B, whereas Aac from Shewanella sp. [32], MacQ [34], PvdQ [52], HacA [38], AiiD [35], Aac from Ralstonia solanacearum [53], QqaR [40], SmPVA [49], AhlM [31], SsCLA [48], SlPA and AuAAC would belong to the AHL acylase group A.

In addition, we have identified two new groups in the phylogenetic tree: an amidase group that includes the AHL acylase from Acinetobacter sp. Ooi24 [33], and a cholylglycine hydrolase (CGH) group that includes PVAs from different bacteria such as A. tumefaciens (AtPVA), P. atrosepticum (PaPVA) [20], Bacillus sphaericus (BspPVA) [54] and Bacillus subtilis (BsPVA) [55]. Furthermore, members of this PVA group differ in their catalytic N-terminal nucleophile residue (cysteine) and subunit composition (homotetramers) compared to some members of the AHL acylase group A that displayed PVA activity (such as SmPVA, SlPA, and AuAAC) which are heterodimers with a catalytic serine at the N-terminal end of their $\beta$-subunit. Moreover, genuine PVAs were proposed to be evolutionary related to bile salt hydrolases (BSHs) [56] like BSH from Bifidobacterium longum [57] and BSH from Enterococcus faecalis [58], forming altogether part of the CGH group of enzymes, and this relationship was confirmed in our phylogenetic tree., Some of the enzymes throughout the phylogenetic tree have been reported to display both penicillin acylase and AHL acylase activities (Figure 4, see enzymes with asterisks), although they belong to different groups. In this sense, Kusada et al. [34] had already suggested that those enzymes with bifunctional QQ and antibiotic-acylase activities might be broadly distributed among the phylogeny, and therefore such bifunctionality could be conserved in other acylases of a wide type of microorganisms. Such assumption has been recently confirmed with new reported enzymes such as PfmA (AHL acylase from Pseudoalteromonas flavipulchra, able to degrade ampicillin but not penicillin G) [51], and AtPVA and PaPVA that are able to hydrolyze both AHLs and penicillin V [20]. Our study demonstrates that two other enzymes from Gram-positive bacteria, such as SlPA and AuAAC, also present this feature, showing not only penicillin acylase and AHL acylase activities, but also aculeacin A acylase activity $[22,24]$.

Taking into account these results, it should be proved whether other members of the phylogenetic tree (apparently those belonging to the AHL acylase group A) could be able to recognize aliphatic 
penicillins and/or aculeacin A as substrates. In this sense, some reports might support such hypothesis; for instance, PVA from S. mobaraensis is able to catalyze the synthesis of aliphatic penicillins and $\mathrm{N}$-fatty-acylated amino compounds [59], whereas cyclic lipopeptide acylase from Streptomyces sp. FERM BP-5809 can deacylate aculeacin A and echinocandin B [48]. On the contrary, Aac from R. solanacearum is not able to degrade ampicillin and aculeacin A, although this enzyme was initially identified as a probable aculeacin A acylase transmembrane protein [53].

Furthermore, the combination of structure-guided multiple alignment and literature mining by $3 \mathrm{DM}$ enabled confirmation of previously determined residue functions and identification of new potential ones. Using the correlated mutations analysis provided by 3DM, we analyzed the 100 most similar sequences to SlPA and identified clusters of residues which have mutated in a coordinated manner within the subset, pointing to their potential involvement in substrate specificity. The heatmap of mutational correlations generated by 3DM (Figure S3) predicted two of residues at the substrate-binding pocket of SlPA (3DM residue numbers 139 and 148 in Table S1). Interestingly, such residues (identified as $\operatorname{Tyr} \beta 24$ and $\operatorname{Tr} p \beta 33$, respectively) had been previously suggested to be positioned at the substrate-binding pocket of SlPA [22]. The other seven residues that showed strong mutational correlations (Table S1: 3DM residue numbers 5, 27, 239, 257, 310, 351 and 595 that correspond in SlPA to Tyr $\alpha 10, \operatorname{Tr} \alpha \alpha 32, \operatorname{Trp} \beta 120, \operatorname{Pro} \beta 150, \operatorname{Gln} \beta 203$, Pro $\beta 266$ and Arg $\beta 544$ respectively) have never been proposed to be located in the substrate-binding pocket of SlPA and may be putatively involved in substrate specificity according to 3DM. Sequence alignment by Clustal Omega allowed to identify the same residues at the equivalent positions in penicillin $\mathrm{V}$ acylase from $S$. mobaraensis, AHL acylase from Streptomyces sp. M664, and cyclic lipopeptide acylase from Streptomyces sp FERM BP-5809 (Figure S4). However, different residues were identified at such positions for other members of the AHL acylase group A, and this result could explain their substrate preference towards AHLs which may differ depending on their acyl-chain length and the presence of the 3-oxo substitution, and their ability to recognize aculeacin A and other echinocandins as substrates. These putative residues might be considered as potential targets for site-directed mutagenesis of this group of enzymes in order to improve their substrate specificity towards different AHLs. Certainly, that would be very useful for some enzymes that show weak activity towards shorter AHLs, such as $\mathrm{C}_{6}$-HSL and $\mathrm{C}_{4}$-HSL, QS molecules produced by Burkholderia and Yersinia [36]. Similarly, mutant variants of these enzymes could be designed with the help of this information and docking simulations in order to more efficient aculeacin A acylases, an approach that has already allowed to prepare mutant cephalosporin acylases that recognize aculeacin A as substrate [60]. Indeed, a similar approach has enabled the obtention of a PvdQ variant with increased $\mathrm{C}_{8}$-HSL activity that could reduce virulence of the human pathogen Burkholderia cenocepacia [61].

In addition, sequence alignment of members of the AHL acylase group A confirmed the presence of a stretch of hydrophobic amino acids encoding a signal peptide, and the conserved glycine, serine, asparagine, histidine, tyrosine and valine residues (Figure S4) that have been demonstrated to be of importance to both autoproteolytic processing and catalysis in Ntn-hydrolases [62-65]. In this sense, Ntn-hydrolases undergo a post-translational processing resulting in a primary pro-peptide that is transformed into an active two-subunit form after the cleavage of signal and spacer peptides $[17,63,64,66,67]$. Essential to this post-translational modification of the pro-peptide, a conserved glycine-serine pair was clearly located in all members of group A of AHL acylases. In this sense, enzymatic activities of both SlPA and AuAAC were abolished when Ser $\beta 1$ was replaced with cysteine, aspartic acid, histidine or lysine by site-directed mutagenesis [22]. In addition, we have also observed in our enzymes the presence of those reported residues that explained the unusual increased size of the hydrophobic pocket in the crystal structure of PvdQ (Leu $\alpha 146$, Asn $\beta 57, \operatorname{Trp} \beta 186$ ) [52]. These conserved residues would correspond to Val $\alpha 141$, Asn $\beta 61$ and Trp $\beta 185$ for SlPA, and Leu $\alpha 136$, Asn $\beta 61$ and $\operatorname{Trp} \beta 181$ for $A u A A C$, respectively. All these observations suggest a similar build-up of the substrate-binding site in all members of the AHL acylase group A that would explain their unique substrate preference for long acyl-chains. Nevertheless, 3DM has allowed for the identification of 
several putative residues (Figure S4) that might explain the reason why some enzymes of this particular group are able to recognize not only long aliphatic acyl chains present in some AHLs and penicillins, but the palmitoyl chain of aculeacin A (such as SlPA and AuAAC) or the linoleoyl chain of echinocandin $\mathrm{B}$ (such as SsCLA), in comparison to other enzymes that show different amino acid residues in the equivalent positions and cannot deacylate echinocandins (such as Aac from R. solanacearum). Additional studies would allow one to determine which residues are actually involved in substrate recognition of different echinocandins, paving the way towards the design of new biocatalysts for the enzymatic production of antifungal compounds.

\section{Materials and Methods}

\subsection{Materials and Bacterial Strains}

Unless otherwise specified, all chemical reagents were purchased from Sigma-Aldrich (St. Louis, MO, USA). Cell culture media were from Difco (Detroit, MI, USA). Streptomyces lividans CECT 3376 and CECT 3377, overexpressing SlPA and AuAAC, respectively, and Chromobacterium violaceum CV026 (CECT 5999), were obtained from the Spanish Cell Culture Collection (Valencia, Spain). For sporulation, S. lividans CECT 3376 and CECT 3377 were cultured on agar plates containing SFM (Mannitol Soya Flour) medium at $30^{\circ} \mathrm{C}$ for $72-96 \mathrm{~h}$. For enzyme production, recombinant $S$. lividans cells were cultured aerobically under submerged conditions in Triptone Soy Broth (TSB) liquid medium at $30{ }^{\circ} \mathrm{C}$ and $250 \mathrm{rpm}$ [68]. C. violaceum CV026 cells (CECT 5999) were grown in Luria-Bertani (LB) agar plates at $37^{\circ} \mathrm{C}$ for bioassays.

\subsection{Synthesis of N-Acyl-Homoserine Lactones}

Pure L-enantiomers of $\mathrm{C}_{4}$-HSL, $\mathrm{C}_{6}-\mathrm{HSL}, \mathrm{C}_{8}-\mathrm{HSL}, \mathrm{C}_{10}-\mathrm{HSL}, \mathrm{C}_{12}$-HSL and $\mathrm{C}_{14}$-HSL were obtained by chemical synthesis (Thomas et al., 2005), with several modifications: $10 \mathrm{mmol}$ of L-HSL hydrochloride were dissolved in $25 \mathrm{~mL}$ of dimethylformamide (DMF), and then $23 \mathrm{mmol}$ of ice-cold triethylamine were added. Later, $14 \mathrm{mmol}$ of corresponding acid chloride was added dropwise with agitation at $4{ }^{\circ} \mathrm{C}$. The mixture was incubated for $2 \mathrm{~h}$ at room temperature and the solvent was evaporated. The product was dissolved in dichloromethane and washed first with $1 \mathrm{M} \mathrm{Na}_{2} \mathrm{SO}_{4}$ and then with a saturated solution of $\mathrm{NaCl}$. Water was eliminated from organic phase by addition of anhydrous $\mathrm{MgSO}_{4}$ and the organic solvent was evaporated. Isolation and purification of the synthesized AHL was carried out by the combination of thin layer chromatography and a silicagel 60 column chromatography (Merck). The elution was performed with an $n$-hexane-EtOAc gradient system. Compounds were visualized in thin layer chromatography by spraying an aqueous solution of potassium permanganate $(1 \% w / v$ $\mathrm{KMnO}_{4}, 6.67 \% w / v \mathrm{Na}_{2} \mathrm{CO}_{3}$ and $\left.0.083 \% w / v \mathrm{NaOH}\right)$ briefly heating. Structures were elucidated by ${ }^{1} \mathrm{H}$ and ${ }^{13} \mathrm{C}$ NMR analysis.

\subsection{Determination of Kinetic Parameters}

The substrate specificity of $A u A A C$ and SlPA, which were expressed and purified as previously described [22,24], was studied using a wide panel of L-enantiopure AHLs including 3-oxo substituted AHLs: $\mathrm{N}$-butyryl-L-homoserine lactone $\left(\mathrm{C}_{4}\right.$-HSL), $\mathrm{N}$-hexanoyl-L-homoserine lactone $\left(\mathrm{C}_{6}\right.$-HSL), $\mathrm{N}$-octanoyl-L-homoserine lactone ( $\mathrm{C}_{8}$-HSL), $\mathrm{N}$-decanoyl-L-homoserine lactone ( $\mathrm{C}_{10}$-HSL), $\mathrm{N}$-dodecanoyl-L-homoserine lactone $\left(\mathrm{C}_{12}\right.$-HSL), $\mathrm{N}$-tetradecanoyl-L-homoserine lactone ( $\mathrm{C}_{14}$-HSL), $\mathrm{N}$-( $\beta$-ketocaproyl)-L-homoserine lactone (oxo- $\mathrm{C}_{6}$-HSL), $\mathrm{N}$-(3-oxooctanoyl)-L-homoserine lactone (oxo- $\mathrm{C}_{8}-\mathrm{HSL}$ ), $\mathrm{N}$-(3-oxodecanoyl)-L-homoserine lactone (oxo- $\left.\mathrm{C}_{10}-\mathrm{HSL}\right), \mathrm{N}$-(3-oxododecanoyl)L-homoserine lactone (oxo- $\mathrm{C}_{12}$-HSL) and $\mathrm{N}$-(3-oxotetradecanoyl)-L-homoserine lactone (oxo- $\mathrm{C}_{14}-\mathrm{HSL}$ ). The methodology employed to detect primary amines released over the course of reactions was similar to that reported in literature $[19,41,69]$. Kinetic studies were performed at $\mathrm{pH} 8.0$ and $45^{\circ} \mathrm{C}$, and all reactions were carried out in triplicate in $100 \mu \mathrm{L}$ of final reaction mixture $(10 \mu \mathrm{L}$ of enzymatic solution, $70 \mu \mathrm{L}$ of $1 \mathrm{M}$ phosphate buffer and $20 \mu \mathrm{L}$ of substrate dissolved in dimethyl sulfoxide, abbreviated as 
DMSO). In order to minimize non-enzymatic conversions, mixtures were kept on ice before initiation and after termination of the reaction. The extent of reactions was then quantified by development with o-phthalaldehyde (OPA). In mild alkaline conditions, OPA is stable and reacts readily with primary amines above their isoelectric point in the presence of $\beta$-mercaptoethanol to form intensely fluorescent derivatives [70]. Thus, each reaction mixture was mixed directly with $100 \mu \mathrm{L}$ of OPA solution (Sigma-Aldrich), which stops the reaction and allows quantification of the acylase activity. The resulting mixture was then incubated for $2 \mathrm{~min}$ at $25^{\circ} \mathrm{C}$ to ensure signal development before reading fluorescence intensity using a FLUOstar Omega (BMG Labtech). Readouts were taken at $25^{\circ} \mathrm{C}$ with $355 \mathrm{~nm}$ and $460 \mathrm{~nm}$ as excitation and emission wavelengths, respectively, with positioning delay of $0.2 \mathrm{~s}$ and 5 flashes per well. This signal, which is proportional to the amount of HSL released during the reaction, was interpolated in a calibration curve of pure HSL to enable expression of reaction rates in non-arbitrary units. The range of substrate concentrations was different for each AHL: from 1 to $25 \mathrm{mM}$ for $\mathrm{C}_{4}$-HSL, from 0.02 to $10.04 \mathrm{mM}$ for $\mathrm{C}_{6}$-HSL, from 0.02 to $5.02 \mathrm{mM}$ for $\mathrm{C}_{8}$-HSL, from 0.002 to $2.040 \mathrm{mM}$ for $\mathrm{C}_{10}-\mathrm{HSL}$, from 0.002 to $1.000 \mathrm{mM}$ for $\mathrm{C}_{12}$-HSL and from 0.002 to $0.500 \mathrm{mM}$ for $\mathrm{C}_{14}$ - $\mathrm{HSL}$; from 0.02 to $1.64 \mathrm{mM}$ for oxo- $\mathrm{C}_{6}-\mathrm{HSL}$, from 0.02 to $8.00 \mathrm{mM}$ for oxo- $\mathrm{C}_{8}-\mathrm{HSL}$, from 0.02 to $1.45 \mathrm{mM}$ for oxo- $\mathrm{C}_{10}$-HSL, from 0.006 to $0.726 \mathrm{mM}$ for oxo- $\mathrm{C}_{12}$-HSL and from 0.002 to $0.080 \mathrm{mM}$ for oxo-C $\mathrm{C}_{8}$-HSL. All reactions were catalyzed by 0.19 and $0.23 \mu \mathrm{g}$ of SlPA and AuAAC, respectively, as these amounts were deemed enough for the hydrolysis of both aliphatic and 3-oxo substituted AHLs. Kinetic parameters were determined by nonlinear regression using Hyper32 program (available on http://homepage.ntlworld.com/john.easterby/hyper32.html). All experiments were performed in triplicate.

\subsection{Inhibition of Violacein Production by Chromobacterium Violaceum CV026}

C. violaceum, a Gram-negative bacterium commonly found in soil and water, produces a characteristic purple pigment called violacein in response to an AHL-mediated QS mechanism [71]. Since $C$. violaceum CV026 is unable to produce $\mathrm{C}_{6}-\mathrm{HSL}$, this mutant strain has been traditionally considered an excellent AHL-biosensor taking into account that violacein synthesis may be induced by AHLs with acyl chains from $C_{4}$ to $C_{8}$ ("forward bioassay"). Although pigment production is not induced if acyl-chains are longer (from $C_{10}$ to $C_{14}$ ), these AHLs can antagonize the common inducers of violacein production ("reverse bioassay") [71]. For the forward assay, C. violaceum CV026 was cultured overnight in LB medium, and then $50 \mu \mathrm{L}$ of culture were used to inoculate the surface of LB agar plates prepared in Petri dishes. Then, $10 \mu \mathrm{L}$ of reaction mixture containing the enzyme (approximately 1 $\mu \mathrm{g}$ ) and the AHLs (20 $\mathrm{mM} \mathrm{C}_{6}$-HSL or $5 \mathrm{mM} \mathrm{C}_{8}$-HSL) in buffer A (potassium phosphate buffer $0.1 \mathrm{M}$, $\mathrm{pH} 8.0$ with $40 \%$ DMSO) was placed in the center of the plate (forward in vivo assay). Alternatively, said mixture could be previously incubated for $24 \mathrm{~h}$ at $40{ }^{\circ} \mathrm{C}$ or $45^{\circ} \mathrm{C}$ depending on the enzyme (SlPA or $A u \mathrm{AAC}$, respectively), and then placed in the center of the plate (forward in vitro assay). Positive ( $\mathrm{C}_{6}$-HSL or $\mathrm{C}_{8}$-HSL in buffer $\mathrm{A}$ ) and negative (buffer $\mathrm{A}$ ) controls were included in each assay plate. All plates were incubated in the upright position overnight at $30{ }^{\circ} \mathrm{C}$ and then examined for the stimulation of violacein synthesis, as indicated by blue/purple pigmentation of the bacterial lawn. The reverse assays for antagonists were carried out identically, except for the fact that a stimulator ( $5 \mu \mathrm{M} \mathrm{C}_{6}$-HSL or oxo- $\mathrm{C}_{6}$-HSL) was added to soft agar together with the CV026 strain. In this case, inhibition of violacein synthesis was reported by the presence of white haloes in a purple background. Forward and reverse assays were optimized by checking the detection limits for each AHL. In this sense, serial dilutions of each AHL were tested and detection limits were defined as the lowest quantity of AHL that produced a visible activation or inhibition of violacein synthesis.

The QS interference by AHL degradation of recombinant S. lividans strains was tested qualitatively using CV026 strain. Firstly, wild type and recombinant strains of $S$. lividans were grown in agar plates containing TSB broth [68]. Tioestreptone $(5 \mu \mathrm{g} / \mathrm{mL})$ was added to the plates used for recombinant S. lividans. Wild type S. lavendulae was grown in agar plates containing SYCC broth [68]. Wild type A. utahensis was grown in agar plates containing sucrose $(3.0 \mathrm{~g} / \mathrm{L})$, soy peptone $(0.5 \mathrm{~g} / \mathrm{L}), \mathrm{K}_{2} \mathrm{HPO}_{4}$ 
$(1.0 \mathrm{~g} / \mathrm{L}), \mathrm{KCl}(0.5 \mathrm{~g} / \mathrm{L}), \mathrm{MgSO}_{4} \cdot 7 \mathrm{H}_{2} \mathrm{O}(0.5 \mathrm{~g} / \mathrm{L}), \mathrm{FeSO}_{4} \cdot 7 \mathrm{H}_{2} \mathrm{O}(0.002 \mathrm{~g} / \mathrm{L}) \mathrm{pH} 6.5$ [23]. All actinomycetes culture plates were incubated for $3-4$ days at $30^{\circ} \mathrm{C}$. Afterwards, $1 \mu \mathrm{L}$ of $1 \mathrm{mM} \mathrm{C} \mathrm{C}_{8}$-HSL solution was added in the growth borderline and then a 15\% soft LB agar inoculated with CV026 was layered on top of actinomycetes cultures. After solidification, plates were incubated for $24 \mathrm{~h}$ at $30^{\circ} \mathrm{C}$. QS interference activity was observed through violacein inhibition.

\subsection{Inhibition of Biofilm Formation by Pseudomonas Aeruginosa on Glass Slides}

SlPA immobilization was achieved by using 3-APTS ((3-aminopropil)-triethoxysilane) and glutaraldehyde. In this study, the method was followed as described elsewhere [72]. Glass slides preparation. Lab-Tek slides (Lab-Tek II Chamber Slide system, Thermo Fisher) were washed by stirring in methanol $(1 \mathrm{~mL} /$ well) to remove any organic contaminant, washed 5 times with distilled water and then $2 \mathrm{~mL} 5 \mathrm{~N} \mathrm{NaOH}$ was added to the cleaned slides, rinsed 5 times with excess water until $\mathrm{NaOH}$ was removed and the water reached $\mathrm{pH}$ 7.0. Slides were incubated with $1 \mathrm{~mL}$ of freshly prepared 3-APTS 10\% (v/v) in water during $2 \mathrm{~h}$ and then washed thoroughly with abundant water to remove 3-APTS molecules not linked to the surface of support. The following steps were done: Soak derivatized slides in freshly prepared $10 \%(v / v)$ glutaraldehyde in deionized water during $4 \mathrm{~h}$ at $25^{\circ} \mathrm{C}$. Rinse 5 times with distilled water to remove any adsorbed cross-linker. Dry the activated slides in the air. The free terminal aldehyde groups must be subsequently cross-linked to amines groups on the enzyme surface through Schiff's base formation by incubating support in the enzyme solutions. Enzyme immobilization. Treated slides were used for immobilization of $0.36 \mathrm{IU} / \mathrm{mL}$ SlPA $(1 \mathrm{~mL} / \mathrm{well}$ at room temperature/overnight) in phosphate buffer $0.1 \mathrm{M}, \mathrm{pH}$ 7.0. One international activity unit (IU) was defined as the amount of enzyme producing $1 \mu \mathrm{mol} / \mathrm{min}$ of 6-APA using penicillin $\mathrm{V}$ as substrate under the assay conditions described elsewhere [28]. Control slides were filled with $1 \mathrm{~mL}$ phosphate buffer $0.01 \mathrm{M}, \mathrm{pH} 7.0$ overnight at room temperature. After incubation, slides were rinsed 5 times with $3 \mathrm{~mL}$ phosphate buffer $0.1 \mathrm{M}$, pH 7.0 per well and incubated in $2 \mathrm{~mL} /$ well $100 \mathrm{mM}$ glycine dissolved in $0.1 \mathrm{M}$ phosphate buffer, $\mathrm{pH} 7.0$ for $30 \mathrm{~min}$ to block any unreacted aldehyde groups during $30 \mathrm{~min}$. Slides were soaked 5 times with $3 \mathrm{~mL} /$ well $0.1 \mathrm{M}$ phosphate buffer, $\mathrm{pH}$ 7.0. The resulting immobilized enzymes can be held at $4{ }^{\circ} \mathrm{C}$ prior to use. The amount of immobilized vs. non immobilized enzymes on slides was determined by measuring penicillin V acylase activity [28]. Only a 33\% of the initial acylase activity was recovered. Chambered slides were used for P. aeruginosa biofilm development by using Luria Bertani broth (LB) as culture media at $28^{\circ} \mathrm{C}$ on a rotary bed shaker $(100 \mathrm{rpm})$. Chambered slides were prepared in four different ways as described before: non-treated; treated with SlPA bound to silanized slides; treated with heat inactivated $\operatorname{SlPA}\left(70^{\circ} \mathrm{C}, 10 \mathrm{~min}\right)$ bound to silanized slides; and SlPA incorporated to LB medium and added to untreated slides. P. aeruginosa was spotted on LB agar and grown overnight at $37^{\circ} \mathrm{C}$. Then, a cellular suspension of 0.1 O.D. $\left(\lambda_{500 \mathrm{~nm}}\right)$ was prepared and inoculated (100 $\mu \mathrm{L} /$ chamber) containing $2 \mathrm{~mL}$ LB . Chambered slides with fitted lids were incubated at $28^{\circ} \mathrm{C}$ for $24 \mathrm{~h}$ in a closed, humidified container. The slides were then carefully washed to remove planktonic organisms, the chamber was removed and the biofilm development was microscopically followed by DIC microscopy (Nikon Eclipse 80i microscope with a Nikon Digital Sight camera). Evaluation of enzyme immobilization by epifluorescence microscopy. This procedure was carried out according to Hormigo et al. [28] with slight variations. Slide-immobilized enzyme was incubated with $5 \mathrm{~mL}$ of phosphate-buffered saline (PBS) $\left(8 \mathrm{~g}\right.$ of $\mathrm{NaCl}, 0.2 \mathrm{~g}$ of $\mathrm{KCl}, 0.2 \mathrm{~g}$ of $\mathrm{KH}_{2} \mathrm{PO}_{4}$ and $1.41 \mathrm{~g}$ of $\mathrm{Na}_{2} \mathrm{HPO}_{4}$ $/ 2 \mathrm{H}_{2} \mathrm{O}$ in $1 \mathrm{~L}$ of water, $\left.\mathrm{pH} 7.4\right)$ containing $1 \%(w / v)$ BSA for $30 \mathrm{~min}$. Then, the glass slide was washed three times with $5 \mathrm{~mL}$ of PBS containing $0.1 \%(w / v)$ BSA and incubated for $2 \mathrm{~h}$ at $37^{\circ} \mathrm{C}$ with $5 \mathrm{~mL}$ of an antibody to SlPA solution prepared in PBS with $0.1 \%(w / v)$ BSA. Next, the biocatalysts were washed again with $5 \mathrm{~mL}$ of PBS containing $0.1 \%(w / v)$ BSA, and incubated for $2 \mathrm{~h}$ at $25^{\circ} \mathrm{C}$ with $5 \mathrm{~mL}$ of Alexa Fluor 488 dye goat anti-rabbit whole antibody conjugate prepared in PBS with $0.1 \%(w / v)$ BSA at a final concentration of $5 \mathrm{mg}$ antibody conjugate/mL. Negative control experiments were carried out to check for non-specific binding of the secondary antibody to the support. Immobilized derivatives were washed three times with $5 \mathrm{~mL}$ of PBS containing $0.01 \%(w / v)$ BSA for $10 \mathrm{~min}$, followed by three 
washings with $5 \mathrm{~mL}$ of PBS for $10 \mathrm{~min}$ and finally three washings with $5 \mathrm{~mL}$ of deionized water for 5 min. The degree of SlPA immobilized on glass slides was then analyzed using an Olympus BX61 epifluorescence microscope at $\times 400$ total magnification. Activity was also determined in silanized glass chambers.

\subsection{Protein Sequence Alignments}

The evolutionary history was inferred using the neighbor-joining method [73]. The percentage of replicate trees in which the associated taxa clustered together in the bootstrap test (1000 replicates) was shown next to the branches [74]. The tree was drawn to scale, with branch lengths in the same units as those of the evolutionary distances used to infer the phylogenetic tree. The evolutionary distances were computed using the $p$-distance method [75] and were in the units of the number of amino acid differences per site. All ambiguous positions were removed for each sequence pair (pairwise deletion option). Evolutionary analyses were conducted in 3DM [45,46] and MEGA X [76], whereas multiple sequence alignment of several enzymes was carried out with Clustal Omega. Optimal global alignment of two sequences were performed using the Needleman-Wunsch algorithm (within Clustal Omega) in order to calculate sequence identity.

\section{Conclusions}

We have demonstrated that reported enzymes, penicillin acylase from Streptomyces lavendulae and aculeacin A acylase from Actinoplanes utahensis, are an interesting extension of hydrolytic (Ntn) enzymes, with potential for biocatalytic applications. They hydrolyze aliphatic penicillins and the antifungal aculeacin $\mathrm{A}$, and are also able to efficiently hydrolyze the amide bonds of several $\mathrm{N}$-acyl-homoserine lactones (AHLs), quorum sensing molecules from Gram-negative bacteria. Furthermore, both enzymes inhibit the production of violacein by Chromobacterium violaceum CV026, and the formation of biofilms by Pseudomonas aeruginosa. In addition, the comparative sequence analysis has revealed high identities between both enzymes and AHL quorum quenching acylases.

These results indicate that penicillin acylase from Streptomyces lavendulae and aculeacin A acylase from Actinoplanes utahensis are involved in QQ processes and both of them could be used for biofouling control in MBR systems and in antimicrobial therapy to prevent colonization of biological surfaces by pathogenic Gram-negative bacteria.

Finally, these enzymes could be considered as versatile biocatalysts, able to hydrolyze the amide bond between an aliphatic acyl side chain and a nucleus containing an amino group, which are present in many substrates (e.g., aliphatic penicillins, aculeacin $\mathrm{A}$ and $\mathrm{N}$-acyl-homoserine lactones), in addition to catalyzing the acylation to obtain new semi-synthetic $\beta$-lactam antibiotic and echinocandins antifungals. Moreover, the phylogenetic study suggests that SlPA and AuAAC could be part of a new family of actinomycete acylases, with a preference towards substrates with long chain aliphatic acyl groups that are involved in QQ processes.

Supplementary Materials: The following are available online at http://www.mdpi.com/2073-4344/10/7/730/ s1. Figure S1: Hyperbolic regression of the activity at different concentrations of several AHLs. Figure S2: Structure-guided phylogenetic analysis of the Ntn-hydrolases superfamily as analyzed from 3DM database. Figure S3: Correlated mutations matrix for the 5C9IA subfamily. Figure S4: Sequence alignment of SIPA and AuAAC with other homologues from the AHL acylase group A. Table S1: Amino acids residues at different positions selected in SIPA according to the structure-based alignment from the 3DM database.

Author Contributions: Conceptualization, J.L.G., C.A., A.S., M.A. and I.d.l.M.; methodology, R.V.-B., D.H., J.F.-L., P.T.-A., Y.A.-U., L.S.-A., A.S. and M.A.; software: R.V.-B., D.H., F.R., M.A. and I.d.1.M.; formal analysis R.V.-B., D.H., J.F.-L., P.T.-A., Y.A.-U., A.I.S., A.S., M.A. and I.d.1.M.; investigation, R.V.-B., D.H., J.F.-L., P.T.-A., Y.A.-U., L.S.-A., A.S. and M.A.; data curation R.V.-B., D.H., A.S. and I.d.1.M.; writing-original draft preparation R.V.-B., F.R., A.S., M.A. and I.d.l.M.; writing-review and editing A.I.S., J.L.G., C.A., M.A. and I.d.1.M.; funding acquisition: C.A. and I.d.1.M.; supervision: I.d.1.M. All authors have read and agreed to the published version of the manuscript. 
Funding: This research was funded by Ministry of Education and Science, Ministry of Science and Innovation of Spain and Comunidad Autónoma de Madrid, grant numbers BIO2008-03928, DEX-580000-2008-31 and S2009/PPQ-1752, respectively; and CTQ2014-60250-R and CTM2016-76491-P projects from Ministry of Economy, Industry and Competitiveness of Spain as well.

Acknowledgments: This article is dedicated to our long-term mentor and collaborator, Carmen Acebal on the occasion of her retirement. We would also like to express our gratitude to both Maria Pilar Castillón and Carmen Acebal for their unconditional support and friendship over the many years dedicated to the Enzyme Biotechnology Group of Universidad Complutense since its foundation.

Conflicts of Interest: The authors declare no conflict of interest. The funders had no role in the design of the study; in the collection, analyses, or interpretation of data; in the writing of the manuscript, or in the decision to publish the results.

\section{References}

1. de Kievit, T.R.; Iglewski, B.H. Bacterial quorum sensing in pathogenic relationships. Infect. Immun. 2000, 68, 4839-4849. [CrossRef] [PubMed]

2. Miller, M.B.; Bassler, B.L. Quorum sensing in bacteria. Annu. Rev. Microbiol. 2001, 55, 165-199. [CrossRef] [PubMed]

3. Chen, F.; Gao, Y.X.; Chen, X.Y.; Yu, Z.M.; Li, X.Z. Quorum quenching enzymes and their application in degrading signal molecules to block quorum sensing dependent infection. Int. J. Mol. Sci. 2013, 14, 17477-17500. [CrossRef]

4. Whitehead, N.A.; Welch, M.; Salmond, G.P.C. Silencing the majority. Nat. Biotechnol. 2001, 19, 735-736. [CrossRef] [PubMed]

5. Soler, A.; Arregui, L.; Arroyo, M.; Mendoza, J.A.; Muras, A.; Alvarez, C.; Garcia-Vera, C.; Marquina, D.; Santos, A.; Serrano, S. Quorum sensing versus quenching bacterial isolates obtained from mbr plants treating leachates from municipal solid waste. Int. J. Environ. Res. Public Health 2018, 15, 1019. [CrossRef]

6. Dickschat, J.S. Quorum sensing and bacterial biofilms. Nat. Prod. Rep. 2010, 27, 343-369. [CrossRef]

7. Whitehead, N.A.; Barnard, A.M.L.; Slater, H.; Simpson, N.J.L.; Salmond, G.P.C. Quorum sensing in Gram-negative bacteria. FEMS Microbiol. Rev. 2001, 25, 365-404. [CrossRef] [PubMed]

8. Williams, P. Quorum sensing, communication and cross-kingdom signalling in the bacterial world. Microbiology 2007, 153, 3923-3938. [CrossRef]

9. Grandclément, C.; Tannières, M.; Moréra, S.; Dessaux, Y.; Faure, D. Quorum quenching: Role in nature and applied developments. FEMS Microbiol. Rev. 2016, 40, 86-116. [CrossRef]

10. Fetzner, S. Quorum quenching enzymes. J. Biotechnol. 2015, 201, 2-14. [CrossRef]

11. Czajkowski, R.; Jafra, S. Quenching of acyl-homoserine lactone-dependent quorum sensing by enzymatic disruption of signal molecules. Acta Biochim. Pol. 2009, 56, 1-16. [CrossRef]

12. Yates, E.A.; Philipp, B.; Buckley, C.; Atkinson, S.; Chhabra, S.R.; Sockett, R.E.; Goldner, M.; Dessaux, Y.; Cámara, M.; Smith, H.; et al. N-acylhomoserine lactones undergo lactonolysis in a pH-,temperature-, and acyl chain length-dependent manner during growth of Yersinia pseudotuberculosis and Pseudomonas aeruginosa. Infect. Immun. 2002, 70, 5635-5646. [CrossRef]

13. Hibbing, M.E.; Fuqua, C.; Parsek, M.R.; Peterson, S.B. Bacterial competition: Surviving and thriving in the microbial jungle. Nat. Rev. Microbiol. 2010, 8, 15-25. [CrossRef] [PubMed]

14. Kusada, H.; Zhang, Y.; Tamaki, H.; Kimura, N.; Kamagata, Y. Novel N-acyl Homoserine lactone-degrading bacteria isolated from penicillin-contaminated environments and their quorum-quenching activities. Front. Microbiol. 2019, 10, 455. [CrossRef] [PubMed]

15. Bzdrenga, J.; Daude, D.; Remy, B.; Jacquet, P.; Plener, L.; Elias, M.; Chabriere, E. Biotechnological applications of quorum quenching enzymes. Chem. Biol. Interact. 2017, 267, 104-115. [CrossRef] [PubMed]

16. Hong, K.W.; Koh, C.L.; Sam, C.K.; Yin, W.F.; Chan, K.G. Quorum quenching revisited-From signal decays to signalling confusion. Sensors 2012, 12, 4661-4696. [CrossRef]

17. Oinonen, C.; Rouvinen, J. Structural comparison of Ntn-hydrolases. Protein. Sci. 2000, 9, 2329-2337. [CrossRef]

18. Utari, P.D.; Vogel, J.; Quax, W.J. Deciphering physiological functions of AHL quorum quenching acylases. Front. Microbiol. 2017, 8, 1123. [CrossRef] 
19. Mukherji, R.; Varshney, N.K.; Panigrahi, P.; Suresh, C.G.; Prabhune, A. A new role for penicillin acylases: Degradation of acyl homoserine lactone quorum sensing signals by Kluyvera citrophila penicillin $\mathrm{G}$ acylase. Enzym. Microb. Technol. 2014, 56,1-7. [CrossRef]

20. Sunder, A.V.; Utari, P.D.; Ramasamy, S.; van Merkerk, R.; Quax, W.; Pundle, A. Penicillin V acylases from gram-negative bacteria degrade $\mathrm{N}$-acylhomoserine lactones and attenuate virulence in Pseudomonas aeruginosa. Appl. Microbiol. Biotechnol. 2017, 101, 2383-2395. [CrossRef] [PubMed]

21. Torres-Guzmán, R.; de la Mata, I.; Torres-Bacete, J.; Arroyo, M.; Castillón, M.P.; Acebal, C. Substrate specificity of penicillin acylase from Streptomyces lavendulae. Biochem. Biophys. Res. Commun. 2002, 291, 593-597. [CrossRef] [PubMed]

22. Torres-Bacete, J.; Hormigo, D.; Torres-Gúzman, R.; Arroyo, M.; Castillón, M.P.; García, J.L.; Acebal, C.; de la Mata, I. Overexpression of penicillin V acylase from Streptomyces lavendulae and elucidation of its catalytic residues. Appl. Environ. Microbiol. 2015, 81, 1225-1233. [CrossRef] [PubMed]

23. Takeshima, H.; Inokoshi, J.; Takada, Y.; Tanaka, H.; Omura, S. A deacylation enzyme for aculeacin A, a neutral lipopeptide antibiotic; from Actinoplanes utahensis: Purification and characterization. J. Biochem. 1989, 105, 606-610. [CrossRef]

24. Torres-Bacete, J.; Hormigo, D.; Stuart, M.; Arroyo, M.; Torres, P.; Castillón, M.P.; Acebal, C.; García, J.L.; de la Mata, I. Newly discovered penicillin acylase activity of aculeacin A acylase from Actinoplanes utahensis. Appl. Environ. Microbiol. 2007, 73, 5378-5381. [CrossRef] [PubMed]

25. Arroyo, M.; Torres, R.; de la Mata, I.; Castillón, M.P.; Acebal, C. Interaction of penicillin V acylase with organic solvents: Catalytic activity modulation on the hydrolysis of penicillin V. Enzym. Microb. Technol. 1999, 25, 378-383. [CrossRef]

26. Arroyo, M.; Torres-Guzman, R.; de la Mata, I.; Castillon, M.P.; Acebal, C. A kinetic examination of penicillin acylase stability in water-organic solvent systems at different temperatures. Biocatal. Biotransform. 2002, 20, 53-56. [CrossRef]

27. Arroyo, M.; Torres-Guzman, R.; de la Mata, I.; Castillon, M.P.; Acebal, C. Prediction of penicillin V acylase stability in water-organic co-solvent monophasic systems as a function of solvent composition. Enzym. Microb. Technol. 2000, 27, 122-126. [CrossRef]

28. Hormigo, D.; de la Mata, I.; Castillón, M.P.; Acebal, C.; Arroyo, M. Kinetic and microstructural characterization of immobilized penicillin acylase from Streptomyces lavendulae on Sepabeads EC-EP. Biocatal Biotransform. 2009, 27, 271-281. [CrossRef]

29. Hormigo, D.; de la Mata, I.; Acebal, C.; Arroyo, M. Immobilized aculeacin A acylase from Actinoplanes utahensis: Characterization of a novel biocatalyst. Bioresour. Technol. 2010, 101, 4261-4268. [CrossRef]

30. Hormigo, D.; López-Conejo, M.T.; Serrano-Aguirre, L.; García-Martín, A.; Saborido, A.; de la Mata, I.; Arroyo, M. Kinetically controlled acylation of 6-APA catalyzed by penicillin acylase from Streptomyces lavendulae: Effect of reaction conditions in the enzymatic synthesis of penicillin V. Biocatal. Biotransform. 2020, 38, 253-262. [CrossRef]

31. Park, S.Y.; Kang, H.O.; Jang, H.S.; Lee, J.K.; Koo, B.T.; Yum, D.Y. Identification of extracellular $\mathrm{N}$-acylhomoserine lactone acylase from a Streptomyces sp. and its application to quorum quenching. Appl. Environ. Microbiol. 2005, 71, 2632-2641. [CrossRef]

32. Morohoshi, T.; Nakazawa, S.; Ebata, A.; Kato, N.; Ikeda, T. Identification and characterization of $\mathrm{N}$-acylhomoserine lactone-acylase from the fish intestinal Shewanella sp. strain MIB015. Biosci. Biotechnol. Biochem. 2008, 72, 1887-1893. [CrossRef] [PubMed]

33. Ochiai, S.; Yasumoto, S.; Morohoshi, T.; Ikeda, T. AmiE, a novel N-acylhomoserine lactone acylase belonging to the amidase family, from the activated-sludge isolate Acinetobacter sp. strain Ooi24. Appl. Environ. Microbiol. 2014, 80, 6919-6925. [CrossRef]

34. Kusada, H.; Tamaki, H.; Kamagata, Y.; Hanada, S.; Kimura, N. A novel quorum quenching N-acylhomoserine lactone acylase from Acidovorax sp Strain MR-S7 mediates antibiotic resistance. Appl. Environ. Microbiol. 2017, 83, e00080-e00117. [CrossRef]

35. Lin, Y.H.; Xu, J.L.; Hu, J.; Wang, L.H.; Ong, S.L.; Leadbetter, J.R.; Zhang, L.H. Acyl-homoserine lactone acylase from Ralstonia strain $\mathrm{XJ12B}$ represents a novel and potent class of quorum quenching enzymes. Mol. Microbiol. 2003, 47, 849-860. [CrossRef] [PubMed] 
36. Sio, C.F.; Otten, L.G.; Cool, R.H.; Diggle, S.P.; Braun, P.G.; Bos, R.; Daykin, M.; Cámara, M.; Williams, P.; Quax, W.J. Quorum quenching by an N-acyl-homoserine lactone acylase from Pseudomonas aeruginosa PAO1. Infect. Immun. 2006, 74, 1673-1682. [CrossRef]

37. Huang, J.J.; Petersen, A.; Whiteley, M.; Leadbetter, J.R. Identification of QuiP, the product of gene PA1032, as the second acyl-homoserine lactone acylase of Pseudomonas aeruginosa PAO1. Appl. Environ. Microbiol. 2006, 72, 1190-1197. [CrossRef] [PubMed]

38. Shepherd, R.W.; Lindow, S.E. Two dissimilar N-acyl-homoserine lactone acylases of Pseudomonas syringae influence colony and biofilm morphology. Appl. Environ. Microbiol. 2009, 75, 45-53. [CrossRef] [PubMed]

39. Romero, M.; Diggle, S.P.; Heeb, S.; Cámara, M.; Otero, A. Quorum quenching activity in Anabaena sp. PCC 7120: Identification of AiiC, a novel AHL-acylase. FEMS Microbiol. Lett. 2008, 280, 73-80. [CrossRef]

40. Koch, G.; Nadal-Jimenez, P.; Cool, R.H.; Quax, W.J. Deinococcus radiodurans can interfere with quorum sensing by producing an AHL-acylase and an AHL-lactonase. FEMS Microbiol. Lett. 2014, 356, 62-70. [CrossRef]

41. Wahjudi, M.; Papaioannou, E.; Hendrawati, O.; van Assen, A.H.G.; van Merkerk, R.; Cool, R.H.; Poelarends, G.J.; Quax, W.J. PA0305 of Pseudomonas aeruginosa is a quorum quenching acylhomoserine lactone acylase belonging to the Ntn hydrolase superfamily. Microbiology 2011, 157, 2042-2055. [CrossRef]

42. Davies, D.G.; Parsek, M.R.; Pearson, J.P.; Iglewski, B.H.; Costerton, J.W.; Greenberg, E.P. The involvement of cell-to-cell signals in the development of a bacterial biofilm. Science 1998, 280, 295-298. [CrossRef] [PubMed]

43. Kohler, T.; Curty, L.K.; Barja, F.; van Delden, C.; Pechere, J.C. Swarming of Pseudomonas aeruginosa is dependent on cell-to-cell signaling and requires flagella and pili. J. Bacteriol. 2000, 182, 5990-5996. [CrossRef] [PubMed]

44. Xia, S.Q.; Zhou, L.J.; Zhang, Z.Q.; Li, J.X. Influence and mechanism of N-(3-oxooctanoyl)-L-homoserine lactone ( $\mathrm{C}_{8}$-oxo-HSL) on biofilm behaviors at early stage. J. Environ. Sci. 2012, 24, 2035-2040. [CrossRef]

45. Kuipers, R.K.; Joosten, H.J.; van Berkel, W.J.; Leferink, N.G.; Rooijen, E.; Ittmann, E.; van Zimmeren, F.; Jochens, H.; Bornscheuer, U.; Vriend, G.; et al. 3DM: Systematic analysis of heterogeneous superfamily data to discover protein functionalities. Proteins Struct. Funct. Bioinform. 2010, 78, 2101-2113. [CrossRef] [PubMed]

46. van den Bergh, T.; Tamo, G.; Nobili, A.; Tao, Y.; Tan, T.; Bornscheuer, U.T.; Kuipers, R.K.P.; Vroling, B.; de Jong, R.M.; Subramanian, K.; et al. CorNet: Assigning function to networks of co-evolving residues by automated literature mining. PLoS ONE 2017, 12, e0176427. [CrossRef]

47. Yasutake, Y.; Kusada, H.; Ebuchi, T.; Hanada, S.; Kamagata, Y.; Tamura, T.; Kimura, N. Bifunctional quorum quenching and antibiotic acylase MacQ forms a 170-kDa capsule-shaped molecule containing spacer polypeptides. Sci. Rep. 2017, 7, 8946. [CrossRef] [PubMed]

48. Ueda, S.; Shibata, T.; Ito, K.; Oohata, N.; Yamashita, M.; Hino, M.; Yamada, M.; Isogai, Y.; Hashimoto, S. Cloning and expression of the FR901379 acylase gene from Streptomyces sp. no. 6907. J. Antibiot. 2011, 64, 169-175. [CrossRef]

49. Zhang, D.; Koreishi, M.; Imanaka, H.; Imamura, K.; Nakanishi, K. Cloning and characterization of penicillin V acylase from Streptomyces mobaraensis. J. Biotechnol. 2007, 128, 788-800. [CrossRef]

50. Terwagne, M.; Mirabella, A.; Lemaire, J.; Deschamps, C.; De Bolle, X.; Letesson, J.J. Quorum sensing and self-quorum quenching in the intracellular pathogen Brucella melitensis. PLoS ONE 2013, 8, e82514. [CrossRef]

51. Liu, N.; Yu, M.; Zhao, Y.B.; Cheng, J.G.; An, K.; Zhang, X.H. PfmA, a novel quorum quenching $\mathrm{N}$-acylhomoserine lactone acylase from Pseudoalteromonas flavipulchra. Microbiology 2017, 163, 1389-1398. [CrossRef] [PubMed]

52. Bokhove, M.; Jimenez, P.N.; Quax, W.J.; Dijkstra, B.W. The quorum quenching N-acyl homoserine lactone acylase PvdQ is an Ntn-hydrolase with an unusual substrate-binding pocket. Proc. Natl. Acad. Sci. USA 2010, 107, 686-691. [CrossRef] [PubMed]

53. Chen, C.N.; Chen, C.J.; Liao, C.T.; Lee, C.Y. A probable aculeacin A acylase from the Ralstonia solanacearum GMI1000 is N-acyl-homoserine lactone acylase with quorum quenching activity. BMC Microbiol. 2009, 9, 89-99. [CrossRef] [PubMed]

54. Pundle, A.; SivaRaman, H. Bacillus sphaericus penicillin V acylase: Purification, substrate specificity, and active-site characterization. Curr. Microbiol. 1997, 34, 144-148. [CrossRef] [PubMed] 
55. Rathinaswamy, P.; Pundle, A.V.; Prabhune, A.A.; Sivaraman, H.; Brannigan, J.A.; Dodson, G.G.; Suresh, C.G. Cloning, purification, crystallization and preliminary structural studies of penicillin $\mathrm{V}$ acylase from Bacillus subtilis. Acta Crystallogr. Sect. F Struct. Biol. Cryst. Commun. 2005, 61, 680-683. [CrossRef] [PubMed]

56. Dong, Z.X.; Lee, B.H. Bile salt hydrolases: Structure and function, substrate preference, and inhibitor development. Protein Sci. 2018, 27, 1742-1754. [CrossRef]

57. Kumar, R.S.; Brannigan, J.A.; Prabhune, A.A.; Pundle, A.V.; Dodson, G.G.; Dodson, E.J.; Suresh, C.G. Structural and functional analysis of a conjugated bile salt hydrolase from Bifidobacterium longum reveals an evolutionary relationship with penicillin V acylase. J. Biol. Chem. 2006, 281, 32516-32525. [CrossRef]

58. Chand, D.; Panigrahi, P.; Varshney, N.; Ramasamy, S.; Suresh, C.G. Structure and function of a highly active Bile Salt Hydrolase (BSH) from Enterococcus faecalis and post-translational processing of BSH enzymes. Biochim. Et Biophys. Acta (BBA)-Proteins Proteom. 2018, 1866, 507-518. [CrossRef]

59. Koreishi, M.; Tani, K.; Ise, Y.; Imanaka, H.; Imamura, K.; Nakanishi, K. Enzymatic synthesis of $\beta$-lactam antibiotics and $\mathrm{N}$-fatty-acylated amino compounds by the acyl-transfer reaction catalyzed by penicillin $\mathrm{V}$ acylase from Streptomyces mobaraensis. Biosci. Biotechnol. Biochem. 2007, 71, 1582-1586. [CrossRef]

60. Isogai, Y.; Nakayama, K. Alteration of substrate selection of antibiotic acylase from $\beta$-lactam to echinocandin. Protein Eng. Des. Sel. 2016, 29, 49-56. [CrossRef]

61. Koch, G.; Nadal-Jimenez, P.; Reis, C.R.; Muntendam, R.; Bokhove, M.; Melillo, E.; Dijkstra, B.W.; Cool, R.H.; Quax, W.J. Reducing virulence of the human pathogen Burkholderia by altering the substrate specificity of the quorum quenching acylase PvdQ. Proc. Natl. Acad. Sci. USA 2014, 111, 1568-1573. [CrossRef] [PubMed]

62. Duggleby, H.J.; Tolley, S.P.; Hill, C.P.; Dodson, E.J.; Dodson, G.; Moody, P.C. Penicillin acylase has a single-amino-acid catalytic centre. Nature 1995, 373, 264-268. [CrossRef] [PubMed]

63. Brannigan, J.A.; Dodson, G.; Duggleby, H.J.; Moody, P.C.; Smith, J.L.; Tomchick, D.R.; Murzin, A.G. A protein catalytic framework with an N-terminal nucleophile is capable of self-activation. Nature 1995, 378, 416-419. [CrossRef] [PubMed]

64. Kim, S.; Kim, Y. Active site residues of cephalosporin acylase are critical not only for enzymatic catalysis but also for post-translational modification. J. Biol. Chem. 2001, 276, 48376-48381. [CrossRef]

65. McVey, C.E.; Walsh, M.A.; Dodson, G.G.; Wilson, K.S.; Brannigan, J.A. Crystal structures of penicillin acylase enzyme-substrate complexes: Structural insights into the catalytic mechanism. J. Mol. Biol. 2001, 313, 139-150. [CrossRef] [PubMed]

66. Li, Y.; Chen, J.; Jiang, W.; Mao, X.; Zhao, G.; Wang, E. In vivo post-translational processing and subunit reconstitution of cephalosporin acylase from Pseudomonas sp. 130. Eur. J. Biochem. 1999, 262, 713-719. [CrossRef]

67. Hewitt, L.; Kasche, V.; Lummer, K.; Lewis, R.J.; Murshudov, G.N.; Verma, C.S.; Dodson, G.G.; Wilson, K.S. Structure of a slow processing precursor penicillin acylase from Escherichia coli reveals the linker peptide blocking the active-site cleft. J. Mol. Biol. 2000, 302, 887-898. [CrossRef]

68. Kieser, T.; Bibb, M.J.; Buttner, M.J.; Chater, K.F.; Hopwood, D.A. Practical Streptomyces Genetics; The John Innes Foundation: Norwich, UK, 2000; ISBN 9780708406236.

69. Clevenger, K.D.; Wu, R.; Er, J.A.V.; Liu, D.; Fast, W. Rational design of a transition state analogue with picomolar affinity for Pseudomonas aeruginosa PvdQ, a siderophore biosynthetic enzyme. ACS Chem. Biol. 2013, 8, 2192-2200. [CrossRef]

70. Švedas, V.J.K.; Galaev, I.J.; Borisov, I.L.; Berezin, I.V. The interaction of amino acids with o-phthaldialdehyde: A kinetic study and spectrophotometric assay of the reaction product. Anal. Biochem. 1980, 101, $188-195$. [CrossRef]

71. McClean, K.H.; Winson, M.K.; Fish, L.; Taylor, A.; Chhabra, S.R.; Camara, M.; Daykin, M.; Lamb, J.H.; Swift, S.; Bycroft, B.W.; et al. Quorum sensing and Chromobacterium violaceum: Exploitation of violacein production and inhibition for the detection of N-acylhomoserine lactones. Microbiology 1997, 143, 3703-3711. [CrossRef] [PubMed]

72. Torabi, S.F.; Khajeh, K.; Ghasempur, S.; Ghaemi, N.; Siadat, S.O. Covalent attachment of cholesterol oxidase and horseradish peroxidase on perlite through silanization: Activity, stability and co-immobilization. J. Biotechnol. 2007, 131, 111-120. [CrossRef] [PubMed]

73. Nei, M.; Saitou, N. The neighbor-joining method: A new method for reconstructing phylogenetic trees. Mol. Biol. Evol. 1987, 4, 406-425. [CrossRef]

74. Felsenstein, J. Confidence limits on phylogenies: An approach using the bootstrap. Evolution 1985, 39, 783-791. [CrossRef] 
75. Nei, M.; Kumar, S. Molecular Evolution and Phylogenetics; Oxford University Press: New York, NY, USA, 2000; ISBN 9780199881222.

76. Kumar, S.; Stecher, G.; Li, M.; Knyaz, C.; Tamura, K. MEGA X. Molecular evolutionary genetics analysis across computing platforms. Mol. Biol. Evol. 2018, 35, 1547-1549. [CrossRef] 